Article

\title{
Towards a Longitudinal Outlook on Industry Transition Management
}

\author{
Kwok Shum ${ }^{1, *}$, Fumio Kodama ${ }^{2}$ and Tomoatsu Shibata ${ }^{3}$ \\ 1 Department of Business Administration, Chu Hai College of Higher Education, Tuen Mun, \\ Hong Kong, China \\ 2 Research Center for Advanced Science and Technology, University of Tokyo, Tokyo 113-8654, Japan; \\ kodama_5@ga2.so-net.ne.jp \\ 3 Graduate School of Economics and Management, Tohoku University, Sendai 980-8577, Japan; \\ shibatatomoatsu@gmail.com \\ * Correspondence: kwokshum@ust.hk
}

Received: 28 July 2020; Accepted: 30 August 2020; Published: 11 September 2020

\begin{abstract}
Innovation has been and continues to be an important theme in management literature, and almost any improvement upon the status quo could be regarded as some sort of innovation. Such an improvement could be made in terms of an increase of efficiency for an existing process or the creation of something new, such as a new process, product, position (perception), or even a paradigm (mental model) (Tidd, Bessant et al., 2005). Not all innovations are therefore the same. Some are more disruptive, while others are incremental, reinforcing the existing order of things. This paper discusses the evolution of innovation as a management concept in the context of a physical product or technology and studies innovation from a longitudinal perspective, i.e., from a single physical product to a product family to smart services associated with the physical products and to the fourth industrial revolution (Industry 4.0) in which physical products are now part of an extensive industrial network, namely the internet of things. How does the theme of innovation (management) change and evolve during this industry transition? More importantly, what are the managerial implications for innovating in the era of Industry 4.0 ?
\end{abstract}

Keywords: product-centric innovation; product platform; service innovations; smart services; digital platform; industry 4.0

\section{Introduction}

Nowadays, products are no longer simply a standalone autonomous assembly of electrical or mechanical components. A thermostat, for example, could first and foremost sense not only the temperature and other characteristics of the ambient, but also be able to act on such information to remotely turn on and off or control other devices to alter the ambient temperature. One could conceive of the thermostat and many other contemporary product systems as smart and connected products [1,2] (Porter and Hepplemann 2014, 2015, Raff et al. 2020). From the product manufacturer's point of view, new functionalities are continually being added or augmented upon the basic physical principle of bimetallic strip (for the case of a thermostat) such that the temperature signal could be sensed and communicated. In this simple setup, innovation could be made in terms of improving the accuracy of temperature measurement, adding communications \& connectivity functionalities, partnering with different makers of devices or systems which the thermostat could "talk to" so that the real-time temperature information could be used in different or as many contexts as possible, re-positioning the thermostat as a control device rather than for mere measurement etc. All of these involve the change of the status quo and could be broadly interpreted and managed as innovation. 
In this paper, we will take a longitudinal perspective of the unfolding of these various sorts of innovative acts and study how firms or companies could "choreograph" the transition, the evolution, or the morphing of their product offerings. Products are conceptualized to undergo a cycle from physical to smart and connected to a cyber-physical system [3] (The National Academies Press 2016). More functionalities are increasingly not embodied in the physical confines of the products, but are outside of products as software in the cloud and contributed by third-party external developers or other members of the ecosystem. What are the implications for product-centric firms to manage this transition in innovation locus and sources? There are at least two points we are raising: (1) Firms must act ambidextrously to innovate both the physical technologies as well as the development of new functionalities in the cyber domain. (2) Firms must fundamentally postulate a new product life cycle, one mimicking the classic Abernathy and Utterback [4] closed and converging cycle, which features an open-ended and diverging phase towards the end as new functionalities are continually added beyond the production of the physical object [1]. Methodologically, we rely on selected case studies and conceptual conjectures [4] in different sectors to articulate and illustrate our ideas and eschew excessive theoretical or empirical details at this stage. Our postulation is largely envelope in nature, outlining the qualitative but essential approach. Future efforts could be devoted to theorize and generalize the ideas in this paper.

The paper is structured as follows: Section 2 revisits the classic Abernathy and Utterback [5] product life cycle associated with a physical product. Section 3 discusses the product platform strategy which raises the discussion of innovation from product level to product family level. Section 4 covers the prerequisites for the servitization of physical products systems as the next stage of industry transition. Section 5 explains smart products and services and the associated business models to implement them. Section 6 offers our own insights of innovation in the era of the Industry 4.0 and explains the digital platform, its underpinning economies, and the ambidextrous management of the cyber and physical domains within a digital platform. Section 7 concludes with some overall comments and potential research directions.

\section{Innovation Associated with a Physical Product}

From a longitudinal perspective, a physical product undergoes a product life cycle [5]. A significant epoch within the product life cycle is that of a dominant design. When a class of new product applications arises, many designs, prototypes, or configurations compete in order to be selected by the industry and its stakeholders. Different designs are proposed by different firms. Ultimately, one particular design comes to dominate and becomes the industry standard, which is stabilizing, so that other complementary efforts or divisions of labor, i.e., who does what, can be coordinated. From an innovation point of view, before the dominant design has arrived, firms' flurry of innovative efforts are directed to maximize the likelihood of its design being selected, these may include product functionality improvement, price performance trade-off mitigation, and even stakeholders coordination etc. After a dominant design has arrived, the focus is paid to improving the efficiency of process of production, an optimizing act across the supply and demand or value chain. Figure 1 depicts the modality of innovation changes from predominantly product innovation to process innovation before and after the dominant design respectively. This implicitly concludes that once a design is stabilized, the product design and manufacturing processes are locked into each other, producing a converging constellation.

So, what are the dynamics of product innovation? A product would usually assume a product architecture which may be integral or modular. A modular architecture is such that the various functionalities of the product can be mapped to respective delineated modules connected by an interface or information rule. An integral architecture is one in which such one-to-one mapping does not exist. Given this formulation, the innovation or innovating of a product could take place at the module level or at the architecture level. In general, innovation at the module level is more confined and incremental while innovation at the architecture level is radical and disruptive. It is 
disruptive because there will be a new partitioning of functionalities, new modules, and therefore a new (shuffling of) value chain players. Incumbent firms would find it disruptive (due to inertia) to re-orient themselves to this new reality as they have been (too) organized to serve the current customers with the existing products or value propositions efficiently.

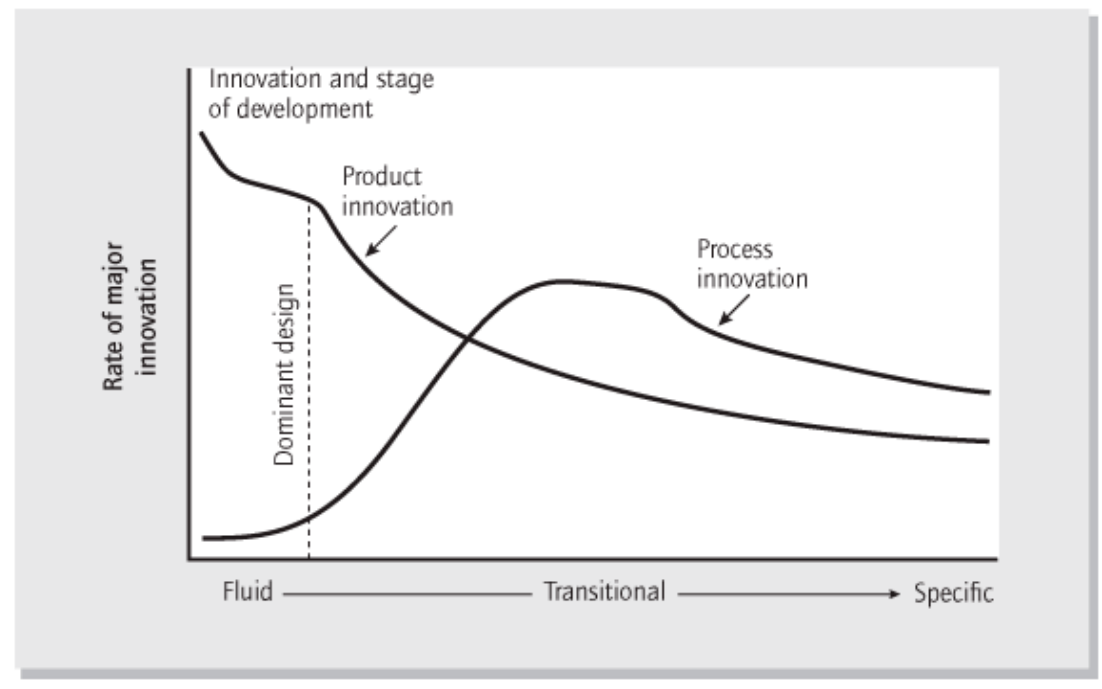

Figure 1. A longitudinal perspective of innovation modalities before and after the occurrence of a dominant design within a generation of product [6].

Kodama [7] suggested a particular type of disruptive innovation known as technology fusion. He asserted that incumbent firms may pursue innovation from a combinatorial viewpoint, integrating technologies from other players in other sectors rather than using a so-called breakthrough approach relying upon its own research efforts within its boundary. The (technology) fusion or integration approach is inherently nonlinear (vs. the linear breakthrough approach) and is similar in spirit to the open innovation in which technologies or intellectual properties could be imported (flowing in) from appropriate owners and exported (flowing out) to appropriate recipients [8]. Technology fusion fundamentally changes the architectural aspects of the products. Shibata et al. [9] carefully traced the architectural development of the numerical controller (NC). NC started with a hard-wired architecture using electronics and hard-wired modules and then moved to a soft-wired modular configuration adopting the microprocessor with a stable interface. This interface was further made public by the company Fuji Automatic NUmerical Control (FANUC, Kofu, Yamanashi, Japan) and enabled a "multi-vender" or open environment, which was of paramount interest as NC as a product category had undergone several changes of its architecture. In the current context, this will lead to a new industry dominant standard and give rise to a new punctuated equilibrium, which will trigger a new industry structure (the multi-vendor environment) and a new iteration of process innovation. Therefore, if a product category undergoes generation changes (e.g., from first to second generation and so on), each new generation would unleash a new product life cycle which would have implications for the incumbents of the previous generation.

The Abernathy Utterback model is also implicitly a closed and convergent innovation cycle. There are several aspects of the model that could be extended. Firstly, manufacturing firms are now increasingly moving downstream and towards servitize their product offers, capturing new revenue, and as a result, the equilibrium or steady state (i.e., settling down to stable constellation of product and process configuration) may not hold true. Manufacturing (processes) now extends beyond the production of the object [1]. Secondly, with the recent retrofitting of physical product with sensors, connectivity and intelligence (e.g., micro-processing) technologies have suggested that more values could be added incessantly and continually even after a product artifact has been produced. 
All these suggest the classic Abernathy Utterback model may need to be refined to capture such new product realities.

\section{Product Family and Product Platform}

For a product configuration which has been "selected" by the market, firms are now rushing to exploit the market potential associated with this product category. There are indeed numerous 'micro' market segments associated with many well-known physical product categories such as: automobiles, electric tools (Bosch, Gerlingen, Germany), inkjet printer systems (Hewlett Packard, Palo Alto, CA, USA), stereo players (e.g., SONY Walkman, Tokyo, Japan) $[10,11]$, etc. Each segment has a unique price and functionality requirement, thus a one-size fits all product strategy would not suffice. On the other hand, it is also too costly to build a product (variant) for each and every identified segment from scratch. To balance the conflicting demands for customization and costs efficiency in product development, a product platform could be utilized.

A (physical) product platform $[11,12]$ is not itself a product. Rather, it is a collective of technology elements which are common across a set of products to be targeted at different micro segments. It could be seen as the highest common factor ( $\mathrm{HCF})$ across all these variants. The different product variants could be developed by mixing and matching these technology elements or building blocks. The SONY Walkman provides a powerful example of such a combinatorial product development strategy; based upon a single product platform, more than 160 variations of the Walkman products (see Figure 2) were introduced from 1980s to 1990s. These variants all share a similar product architecture or product platform consisting of (1) a miniature stereo headphone, (2) a super-flat motor, (3) a tape drive, and (4) a rechargeable nickel-cadmium battery. Different Walkman models would consist of different versions or levels of these four building blocks.

\section{Product Platform \& Product Derivatives}

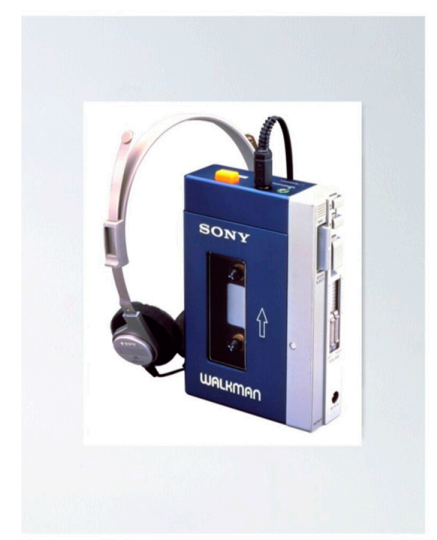

- More than 160 variations (derivatives) of the Walkman products were introduced from 1980 to 1990

- They are all derived from a product platform of

- Miniature stereo headphone

- Super-flat motor

- Tape drive

- Rechargeable nickel-cadmium batteries

Figure 2. A particular model derived from The SONY Product Platform [11] (Meyer and Lehnerd 1997).

FANUC, which is maker of numerical controller in Japan, has also adopted a product platform/family strategy; since the exact configuration (or architecture) of a numerical controller could not be determined prior to its connection or retrofitting to the machine tool under concern, numerical controller is therefore made to order in nature and could not be mass-produced a priori. For such products, it is best to conceptualize them at the level of building blocks which are used to assemble the final system. Indeed, FANUC's product family consisted of different series, comprising either integral or modular product architecture to meet different end users' needs [9].

Each building block undergoes evolution and upgrade of its own and the mixing and matching of them lead to newer variations and generations of products. An implicit assumption of platform-based growth is that the platform architecture is modular so that the modules that implement a particular function could be reused across different variants and generations with minimal disruption - the plug 
and play conveniences. It is possible to suggest that platform-based innovation is incremental rather than qualitative. However, leveraging minor adjustments to address different customer requirements makes the platform an efficient and effective product development strategy. The economics of product platform or variety-based growth, however, needs to be understood in order to appreciate the critical successful factors of product platform. Intuitively, variety would forfeit the production learning associated with the mass production of a homogenous product. This variety vs. efficiency dilemma needs to be resolved.

\section{The Economics of Product Platform}

To understand the economics of mass customization based on a product platform, Shum [13] used a mathematical model to study the interactions of the product variants, there are two categories of interaction: (1) during production of the variants and assuming that spillover (production) learning exists among their production and logistics using the same production or supply and value chain infrastructure; (2) interactions among the variants in the product markets as one variant targeting toward one market segment may cannibalize another variant targeting towards an adjacent segment; the first interaction could be counted as positive externality while the second interaction could be counted as negative or congestion effects due to "similar variety"; overall, their model found that to mitigate or to internalize cannibalizations, platform firm needs to effectuate spillover production learning among the production of the product (derivatives), a notion introduced as cross-learning $[13,14]$. To fix ideas, suppose there are three product variants derived from a given product platform, then the production (costs) learning of any individual product must need to benefit from not only its own cumulative production volume but also from the total cumulative production volume of the other two products, amidst less effective, as a condition in order to mitigate the congestion or cannibalization in the product marketplaces. This is the concrete meaning of cross-learning and makes explicit the importance of knowledge transfer among product lines derived from the same platform. This learning framework is also qualitatively similar to learning by porting to be addressed in Section 6 of this paper.

Another "parameter" of a product platform is that of the degree of openness; the above platform-based product development activities are all "confined" to within the boundary of a company; i.e., all the product variants and derivatives are developed within the firm. There are now physical platforms which are open; i.e., the development works in the downstream allow or admit participation from developers not associated with the company. For example, OPENDESK, which is an online marketplace that hosts independently designed furniture (platforms) and connects its (end) customers to local makers or developers around the world. The developers could customize the general furniture platform for local needs. The open product or furniture platform is building a distributed and equitable supply chain (as it allows local social development) through a global maker (developer) network. The economy of production associated with this open marketplace is that of economy of scope or cross-learning among the different furniture projects implemented worldwide facilitated by knowledge transfer within a (moderated) community of developers.

\section{Servitization}

Increasingly, manufacturing or product centric firms think beyond product offerings and are moving downstream to provide direct services to the end user aftermarket. These include the conventional service items such as maintenance, spare parts inventory, training etc.; from the supplier's point of view, this could create new revenue stream, e.g., Hewlett Packard (HP) printer as a product, while undergoing the conventional product life cycle as explained above, draws a recurring revenue from the sales of the associated ink jet cartridges. Other more complicated products or systems subscribe to such similar service logics but have the potential to be associated with a wider scope of service activities and over the life cycle of the product. This applies to more complicated or complex systemic products, e.g., for a complex product system of MRI (magnetic resonance imaging), service opportunities lie in the following areas [15]: 
1. determining requirements and whether having a scanner is justified (pre-consultative sales),

2. financing the scanner,

3. installing the scanner,

4. testing, calibrating, and validating the scanner,

5. maintaining and replacing parts,

6. replenishing materials (gases and imaging media),

7. training personnel to use the scanner,

8. determining a patient's need for a scan (preliminary diagnosis),

9. preparing the patient for a scan,

10. scanning the patient,

11. interpreting the scan,

12. updating the software,

13. upgrading the hardware etc.

This "menu" of services ranges from pre-sales consultation to those concerned with operations and maintenance of the equipment. As we will cover in the next section on smart services, if the equipment are equipped with sensors, connectivity and intelligence technologies, more proactive services could be developed based on the data regarding the real time status of the system. Without losses of generality, the service challenges of product-centric firms, in the provision of either conventional or smart services, lie in the acquisition of new technologies and the coordination of more partners and could be framed according to these two dimensions [16].

\subsection{Social Technology Dimension}

Due to product firms now having to provide more "services" to end customers, the relationship goes beyond a one-off, arms-length product sales transaction and there are more interactions between the product firm and its customers. Additional service activities have to be performed but by whom? Product firms could choose to internalize or vertical integrate such new service activities or outsource them to the market. The criteria may involve balancing the opportunism and transactions costs factors with the efficiency of the third party. If the former outweighs the latter and if the product firm possesses the competencies to perform those service activities, it will keep them inside the company, i.e., the make stance. On the other hand, if the latter outweighs the former, then the product firm would rely on the market to provide those new service activities, i.e., the buy stance. There is therefore a classic make or buy decision embedded in the service stage. These two different ways to coordinate the division of labor in the provision of a given set of service activities could be conceptualized as a social technology [17]. Social technology concerns with the organization and coordination aspects rather than the actual production aspects. For the same procedure, there could be several alternatives to divide up the tasks and activities, and to incentivize different parties to perform those tasks. In some instances, firms could use both intra-organizational and inter-organizational networks [18] in the development of novel products and services. Such networks are examples of social technology.

\subsection{Physical Technology Dimension}

In the provision of new service activities, product-centric firm may also need to deploy or acquire new technologies in order to complete the tasks. New technologies such as new measurement equipment and systems, sensors, connectivity, computation technologies etc. A physical technology refers to the implementation of a scientific principle in the physical domain. For example, photo-electricity refers to the principles of how an energetic photon knocks off an electrons within suitable semiconductor materials to create a flow of electrons or the electric current. This scientific principle is in turn being implemented by the solar photovoltaic cell (the PV cell). To operate a solar PV system, one needs not only PV solar cell and panels, but also a host of other technologies such as the inverter electronics technologies, the battery technologies etc. Similarly, for the provision of the new service activities, 
a product-centric firm may need to acquire and operate new physical technologies. The operation of such physical technologies may again involve new expertise and competencies or new stakeholders or suppliers which again reinforces the needs to consider social technology mentioned.

We can now generalize our discussion of the transition of a product -centric firm to service, as in Figure 3 [16]. The most challenging and complicated case is the one scenario illustrated in the top right quadrant whereby both new physical technology and social technology or organization are involved and they need to co-adapt before a stable configuration could arrive to deliver the new service activities.

\section{Transition from Products to Services}

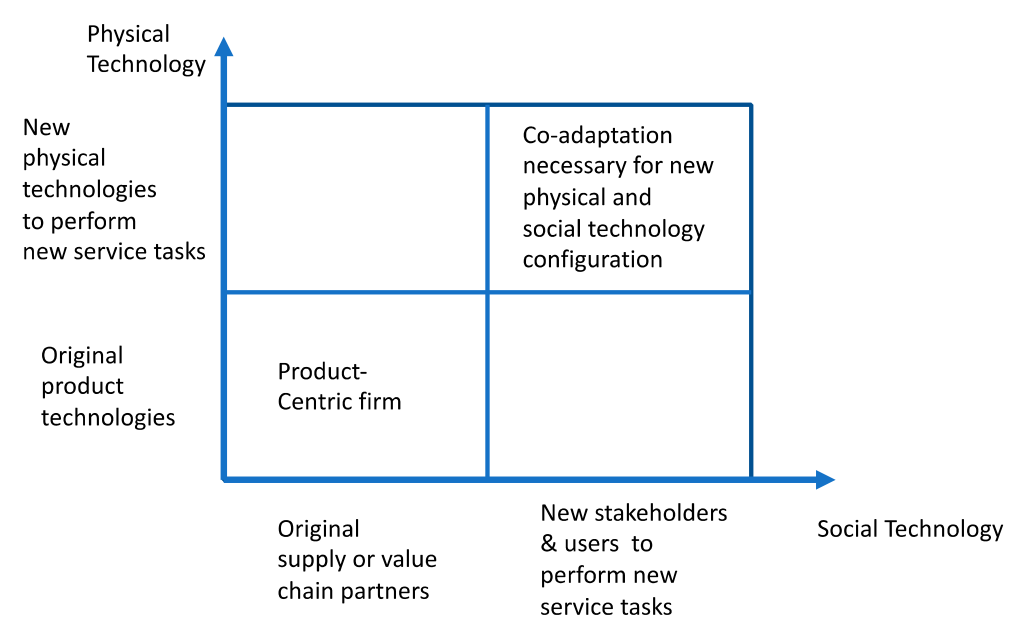

Figure 3. Conceptualization transition from product to service: a social technology and physical technology approach [16].

\section{Towards Smart Services}

\subsection{What Is a Smart Product?}

Smart services go beyond the kinds of upkeep and upgrades a product-centric firm may be bundling with its products, as mentioned in the preceding section. A pre-requisite of a smart service is to build intelligence into products, along with sensors and connectivity technologies. Smart services are usually associated with a class of smart and connected products [1] which will have major implications to companies and competition.

Raff et al. [2] develop a taxonomy of smart product archetypes: digital, connected, responsive, and intelligent. A digital camera with hardware and organization software installed within the product is an example of a digital product as it meets all the criteria to capture, store, process and provide image data; a connected product is empowered by communication software so it may wirelessly connect to, engage and create value by being embedded in an assemblage of products. There is thus a network level of functionality co-created by the members of the networked systems and products. Examples are smart lighting system consisting of the smart networkable hue bulb, the user's smart phone, music system, and the smart home assistant, all these could be coordinated to give rise to services such as remotely to turn on the light bulb, or to operate the light using voice etc. Responsive products are furnished with connectors, sensors and actuators and sensing and responding logic. They can not only connect to an extended network, but also sense and gain awareness as well as react to input signals. This category of product is an exemplar of how the physical product domain and the data (cyber) domain are interacting which has important implications to product development in the physical product domain. An example of a responsive product is the Amazon Dash Smart Shelf [2] (p.18) which is equipped with hardware and connectors, sensors. The sensors will instruct virtual actuators to trigger a [purchase] order as soon as a given physical quantity falls below a critical 
threshold level. From a product development point of view, the trigger could also act on other sensors signals (an "or" Boolean function) are found to correlate with the original physical quantity signal. New sensors of different physical principles would have implications to product development or technology fusion or integration in the physical domain as would be discussed in the next section. Lastly, an intelligent product is equipped with the full "stack" of hardware functionalities, software, connectivity, and AI (artificial intelligence) software. It is able to recognize patterns, reason and learn from growing complex data sets and respond accordingly. An example is the Google NEST learning thermostat [2] (p. 19) which learns and trains itself to predict which room climate its users like at different periods of the day. It could also help save energy by switching to eco-temperature when it senses that nobody is at the premise.

\subsection{Smart Services}

In manufacturing settings, these different hierarchical capabilities (from digital to connected to responsive to intelligent) at the product level will start to generate immense data about how the products are being used, their status in the field and which could be continually logged and communicated back to the manufacturer. Armed with this type of intelligence, product-centric firms could proactively diagnose the situation, forecast an event, and intervene the operations via actuation. For customers, smart services therefore create an entirely new kind of value-the value of removing unpleasant surprises from their production schedules due to e.g., the unexpected and premature failure of the products. Such services could be labelled zero downtime or business continuity services.

More generally, according to Allmendinger et al. [15], there are four types of business model to organize the provision of smart services; these models could be broadly classified in terms of a division of labor between the product-centric firm and other stakeholders; the embedded innovator and the solutionist models refer to strategies in which the extra service activities, such as sensing and the provision of new service items, are all integrated into the product-centric firm itself; on the other hand, the aggregator and the synergist models refer to new service activities, located at the adjacencies, (i.e., the adjacent stages upstream and downstream in the service value chain) be provided by other stakeholders and to be coordinated by the product-centric firm. It is our contention that the richer the set or menu of new smart services to be developed, the more extensive the coordination to be achieved, and this would overwhelm the vertical integration model and therefore favor the emergence of the aggregator and synergist models. Again, the message here is that while smart services are technology-enabled, the organizational or social technology aspect is critical in their design and development.

Shum [19] had adopted a similar framework to study and compare the optimal organization of value chain in the midst of the digital convergence of solar photovoltaic (PV) leading to smart PV. He had argued that (open) industry and communications standards (aka the open deployment model), along with standardized programming language may be an alternative to vertical integration (aka the closed deployment model) in addressing the intermittency issues associated with solar PV as well as the coordination in new energy services development by an increasing diversity of developers after ICT (information and communications technology) is retrofitted to an otherwise mechanical and electrical PV system. So, if we consider addressing intermittency as a "service" to be provided to solar PV system after it is sold, the closed model will emphasize a hardware approach (e.g., by the installation of a battery storage) from the product-centric firm while the open model will gravitate towards a communications and programming approach using open standards and involving external programmers and developers to develop electricity trading services among PV systems owners towards the citizen utility concept [20].

\subsection{Beyond Smart Services}

The data generated turns out to be of values themselves both internal and external to the product-centric firm. 


\subsubsection{Product Development}

Internally, because the field intelligence and data make product performance and customer behaviors visible as never before, product firms gain unprecedented feedback to support their research and product development efforts concerning how newly designed features are received in the field and gain insight into customers' needs [1,14].

\subsubsection{Smart Product as a Service}

The field data or intelligence could be more comprehensively leveraged beyond just smart services. The same set of data could be reused in different contexts, provided that there is the next use case to be developed. A product-centric firm may actually never foresee the potential types of services which could be developed; view this way, the product could be positioned as a platform (or product as a (service) platform) to provide many values to many stakeholders other than the product user and the product supplier himself. For example, Porter and Hepplemann [1] suggested that smart and connected products let firms switch from [transactional] selling products to selling products delivered as a service. One prominent example is Fuji Xerox's shift from selling copiers to charging by the document or the so-called document management services (DMS). Copiers retrofitted with the digital connected responsive intelligent capabilities are able to support new business models which subsume the elements of smart services provision. This is clearly an evolution from smart services provisions to enabling new business model or mental model, which is a positioning or even a paradigm innovation as mentioned in the beginning of this article. Such an evolution also has product development implications. As the product-centric firms now retain ownership of the products, it is then their incentive to develop the products in the field to be more robust rather than "planned obsolescence".

As industry is transitioning to the Industry 4.0 era, any product-centric firms would face an increasing diversity of devices and systems to be connected to their products, an increasing diversity of content, data to be generated, and an increasing diversity of developers and stakeholders, and an increasing diversity of new business models. This is a step-up challenge and will necessitate thinking about strategies to manage this complexity. The smart service stage could be seen as an intermediate stop to the transition to Industry 4.0. An important corollary is that the choice of social and coordination technology at the smart service era would enable or constrain a product-centric firm's transition to the Industry 4.0 era.

\section{Industry 4.0: From Product to Network of Products}

The 4th Industrial Internet or Industry 4.0 could be considered a smaller subset of the larger trend or paradigm of the Internet of Things (IOT). IOT is the network of devices such as vehicles, and home appliances etc. that contain electronics, software, sensors, actuators, and connectivity which allows these things (technologies) to connect, interact and exchange data. IoT therefore involves extending Internet connectivity beyond standard devices, such as desktops, laptops, smartphones, and tablets, to any range of traditionally dumb or non-internet-enabled physical devices and everyday objects. Embedded with technology, these devices can communicate and interact over the Internet, and they can be remotely monitored and controlled (Wikipedia).

In the context of industrial internet, all kinds of physical production systems which are not networked before, are now linked to share information and implement actuation or decisions after the data from individual systems are pooled and analyzed in the cyber domain. There is naturally a clear division of labor between the physical domain where the machines actually sit and the cyber domain where the data about the machines are analyzed and computed to give a new round of instructions to the machines. Industrial Internet or IOT therefore assumes a cyber-physical system (CPS) architecture [4]. The detailed architecture of such a CPS system such as edge, fog, and cloud and the multitude of middleware and data format is beyond the scope of the current concept paper. However, we illustrate several points for discussion in the context of the current paper: 
(1) New applications at the network level emerge compared with applications at the individual machine level, e.g., FANUC, which was discussed earlier in the section concerning the dynamics of product architecture and product family, now has developed the FIELD (FANUC Intelligent Edge Link and Drive) cross-connectivity data system across its own product lines (NC, robots, robo-machines etc.) and other brands' products so that the collective could be monitored and managed to deliver zero down time (ZDT) service for the networked system, an attribute beyond that at the level of the individual system. It is conceivable that this network attribute is more useful than the same attribute at the individual equipment level. Other system level services include: production monitoring analysis (PMA) and, besides ZDT and PMA, which are developed by FANUC itself, FANUC made available the converter interface (communication standards and protocols) which allows many different brands and makes of products or equipment to be integrated into FANUC's FIELD network.

(2) This promotes a "multi-vendor" hardware environment. Likewise, FANUC also develops FOCAS (FANUC Open CNC API Specification) so that "third party" developers could now use the FANUC's APIs to write apps to be run or operated on the linked systems. API refers to an application programming interface which provides a "hook" for third-party developers to access data and services owned by FANUC to build apps quickly [21]. All the apps developed by third party developers would be vetted by FANUC and once approved, would be made available for purchase in the FIELD system store (like an app store). It is now clear to conceptualize that FANUC is taking a lead in writing its own digital playbook to build or orchestrate its industrial internet ecosystem which consists of more and more makes and brands of equipment vendors on one side, and more and more third-party apps developers to write industrial apps in the other side; more and more end customers are also willing to participate.

(3) Formally, FANUC is organizing an OPEN multi-sided digital platform to orchestrate these different categories of stakeholders. Figure 4 (adapted from FANUC's own corporate materials) depicts the open platform consisting of third-party apps developers and equipment vendors.

\title{
FANUC Industrial Internet Ecosystem
}

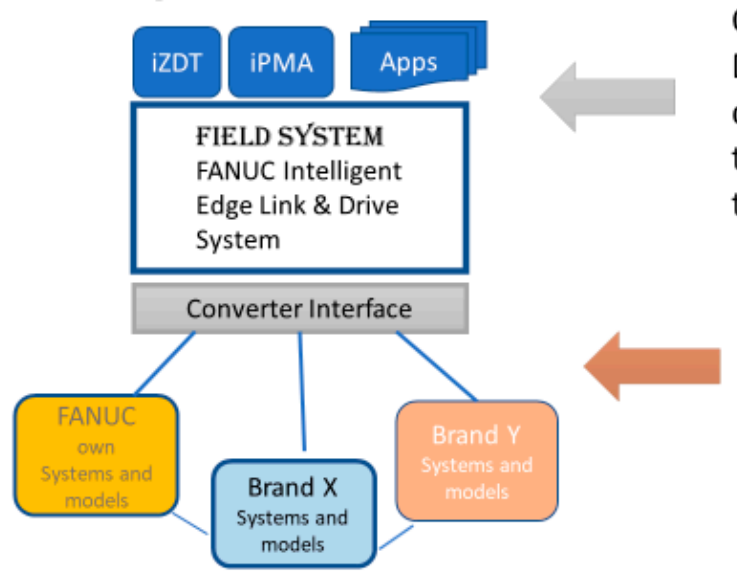

Cyber world: APIs, Software

Development Kit allow third party

developers (including end users)

to develop apps which are sold

thru FANUC FIELD system store

\author{
Physical world (network of things): \\ connecting FANUC's own product lines and \\ those of other vendors (the multi-vendors \\ environment)
}

Figure 4. A Layered Structure of the FIELD system (FANUC); Source: FANUC corporate materials on the Internet) and the Industrial Internet ecosystem (Authors' rendition).

\subsection{Economics of a Digital Platform}

Underpinning the operation or growth of this digital platform is two sources of economy. (1) A low marginal cost of participation; e.g., once a vendor has successfully developed a converter interface to connect its first machine to the FIELD network, then it is virtually costless (of zero marginal cost) to connect the "next" equipment of its own brand to the system. This is the characteristic of "increasing 
return" for a typical information good product (such as software); this zero marginal costs will encourage the proliferation of connection of devices (equipment and sensors) from one brand to the next brand, sustaining both direct and indirect network externality (direct externality for equipment of the same brand; indirect network externality for spillover among different brands of equipment and different categories of equipment and devices etc.). (2) The so-called learning by porting economy proposed by Kodama [22,23]. Both sources unfold a deeper meaning of learning by porting, and the following scenario would demonstrate this.

Suppose an industrial app was written for FIELD by FANUC or a third-party developer, it is then ported to the whole network of connected systems to deliver the new functionality; as there is increasing number of apps in the FANUC system (app) store month by month, these various apps could be run on top of the FIELD open platform; it is very similar to the case where an iPhone is concurrently running many apps for different purposes on the IOS platform. However, the implementation of such software-based functionalities involves no changes in the architectural aspect in the physical domain. And porting after porting is made easier and easier (that is why we could name or invent a new mode of learning called: learning by porting) via the (stabilized) family of APIs and software development kit (SDK). This seems to be an important economic principle of the unfolding Industry 4.0 or Internet of Things in general.

However, what do we mean by learning? Moreover, what are the activities to be learnt? Here, we could suggest the essential "production activities" in the cyber domain are the developing, porting, and continual versioning of the original app using a given software development kit SDK. The learning is contingent upon how the knowledge of developing an app is cumulated, archived, and shared among developers which is very similar to the notion of cross-learning suggested in Section 3 of this paper. We could then propose that the role of the owner of the digital platform, in this case FANUC, or any other platform owners at the industry level, is to develop rules and the learning infrastructure to facilitate and incentivize such knowledge transfer among developers using the same SDK. This is likened to Rosenberg's [24] notion of 'machinofacture'. This development could also benefit by the idea of a software factory and waterfall approach [25] in which app development productivity for a digital platform could be enhanced by standardized processes, modules reuse, and continuous improvement by way of the Kaizen methodology. Apple Computers, e.g., institutes its own Apple Developer program which allows developers to get access to beta software, advanced app capabilities, extensive beta testing tools, and app analytics.

Learning among project or apps developers is an important source of economy of production in the Industry 4.0 era, in particular in the cyber domain, and this is an important observation and assertion. This could be facilitated by standardized apps development processes or infrastructure as captioned above, as well as knowledge transfer and sharing among developers organized as a community of practice $[25,26]$.

More empirical studies of such learning mechanisms should be pursued. Why would such developers have the incentives to share knowledge among each other? First, different apps developers are not exactly competing with each other in the product marketplace because their commonality is just using the (same) FIELD platform to implement their apps functionalities. The digital platform owner has an incentive to facilitate knowledge sharing because if there were more apps developed for the platform, this would attract more equipment vendors and industrial customers on the other sides to join the platform. These other equipment vendors all want to jump on the bandwagon in the physical domain and to be included so that they could be covered in the apps solutions to be developed by the large contingent of app developers. This would lead to a virtuous cycle of platform dominance or even perpetual growth up to a certain point. The dual economic sources of increasing returns associated with a digital platform could be summarized using Figure 5 . 


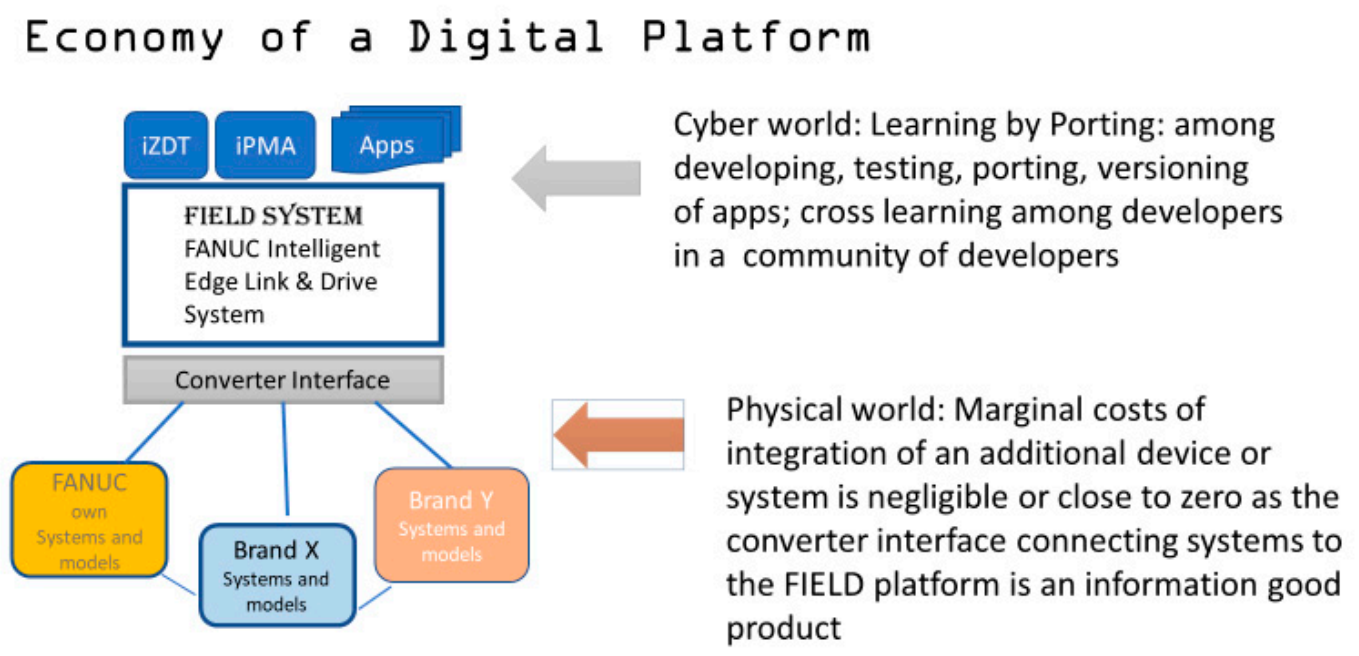

Figure 5. Illustrating the essential economies of an OPEN two-sided digital platform.

\subsection{Digital Platform as a Coordination or Social Technology}

At this stage, it is possible to halt and deliberate a critical issue in the Industry 4.0 era, if so many additional (service) functionalities are to be augmented ex-post (i.e., after) development of the hardware, how should a firm like FANUC or any general digital platform owner at the industry level organize such ex-post innovation activities? If a firm needs to go out to the market and search and coordinate these external third-party developers, the search and coordination costs would be prohibitive.

The neo-classical firm theory (theory of firm) explores the economic rationale or meaning of the boundary of a firm. According to Professor Ronald Coase (the Nobel Laureate of Economics in 1991)'s paper "The Nature of the Firm" [27], he suggested that a firm's boundary exists because the economic activities which are now organized within the firm are, otherwise, too costly to be sourced from the market (due to the difficulty finding a supplier or too many uncertainties or contingencies to be covered in a contract etc.) as an alternative. As a result, it may be better for firms to organize and provide those activities themselves rather than to "buy" them.

As we have mentioned in our discussion, the organization of a digital platform by a product centric-firm, such as FANUC, or in general, one which releases a set of APIs to allow third-party developers to develop apps using a SDK to be ported into its industry 4.0 network, economizes the search, coordination, and transaction costs of dealing with the developers. This is above and beyond the smart service paradigm which was discussed in the prior section in which firms could play the role of aggregator and synergist to develop new services in a pre-emptive or even self-propagating fashion. While firms in the smart services era also need to partner with other stakeholders and need to economize such behavioral oriented costs in service development, the discussion there stops short of the organization of an explicit digital platform to coordinate the developers.

This digital platform, in the context of firm theory, could be conceptualized as an alternative organizational form [28] blurring the distinction between firm (hierarchy) and market, it (the digital platform) is owned by the firm and could extend its boundary. The developers of services or apps in the downstream contribute to the firm but are not part of the firm. Rather, they are loosely coupled to the firm and needs to continually interact with the firm to get the update in, e.g., the API specification.

The coordination advantage associated with a digital platform could easily be turned into a strategic advantage. The more apps developers a digital platform "hosts," the larger the set of offerings to be run on the system (e.g., FIELD) of linked machines which consists of products from FANUC and other vendors, this will improve the likelihood such brands or makes would be purchased because the end users (the customers using the machines) know that there are many services or apps in the apps store for different manufacturing applications, scenarios, and objectives which will cover those brands. A larger and more diverse base of machine makes, models, and brands will in turn attract more app 
developers to the digital platform because such varieties in the physical domain will give rise to new combinations of manufacturing requirements, scenarios and programs or apps; this kind of increasing return [29] or virtuous cycle dynamics would prove to be the most critical strategic asset and entry deterrence in the era of Industry 4.0. It is also interesting to further assert that, in the Industry 4.0 era, the calculus or strategy of competition such as that enshrined in the Porter's five forces framework needs to be rewritten as competitors could cooperate alongside one another in the digital platform rather than engage in the zero-sum, cut-throat sort of competition.

\subsection{Towards Ambidextrous Management in the Industry 4.0 Era}

The above has portrayed both sides of the digital platform as apps developers and equipment and systems vendors. They represent the cyber and physical domains respectively. Our intention is to highlight that at the Industry 4.0 era, both the physical domain and the cyber domain play important and reinforcing roles to support the growth of the digital platform.

The dynamics of interaction of both sides can best be studied from the data perspective. We follow the notions of IBM (IBM Big Data and Analytics Hub) which suggests the 4Vs property of data generated in the digital platform of Industry 4.0 era, namely velocity, volume, veracity, and variety of data. Of particular analytical interest to us is the notion of the variety of data. The data generated by a large and diverse equipment installed base in the network in the physical domain could be structured or unstructured even covering, e.g., some emotional comments and discussions about the products on various types of social media. The processing or analysis of such data in the cyber domain by various methodologies, such as artificial intelligence or deep learning, could facilitate the demand articulation process [7] with respect to how products in the physical domain should be developed (see also Section 5.3.1 of this paper).

In the cyber domain, as more variety of data from the industry equipment networks or even from external data marketplaces are merged and being analyzed, more patterns are expected to be recognized, and more correlation among data are expected to be discovered. Such knowledge could lead to new decision logics and rules for controlling the equipment in the physical domain. New sources of data mean more sensors of different physical principles would need to be designed into the physical products in order that such sensors data could feed into the new decision rules. In the interim, new analytical capabilities or algorithms need to be developed (by entrepreneurs) in the cyber domain in order to tackle the diversity of convoluted data.

In general, the increasing velocity, volume, and veracity (uncertainty) in data, even processed by suitable algorithms, would demand increase in actuation capabilities in the physical domain such as e.g., improved range of operations parameters, from hard-wired modules to soft-wired modules with improved processing speed via the adoption of MPU (e.g., in the earlier days of FANUC), more intelligences to be resided or designed into the local physical products etc. All of these have major product development implications in the physical realm. Such innovations could be facilitated in terms of the importation of new technologies via technology fusion or integration, or open innovation and may involve the change or evolution in the architectural aspects of the original product technology [2] (p. 19).

Therefore, the $4 \mathrm{Vs}$ of data would trigger a new innovation management cycle (covering product, process, platform (architectural) innovations etc.) in the physical domain reflecting that the physical and cyber domains are intimately linked in the Industry 4.0 era. The interaction (see Figure 6) or feedback between the two sides must be managed as a unit of analysis lest one side becomes the bottleneck of the other side and vice versa. This kind of dilemma could best be addressed by the notion of ambidextrous development $[30,31]$ of managing both domains simultaneously. It could also be conceptualized as a co-evolutionary development of both sides. 


\section{Interaction Between Physical and Cyber in a Digital Platform}

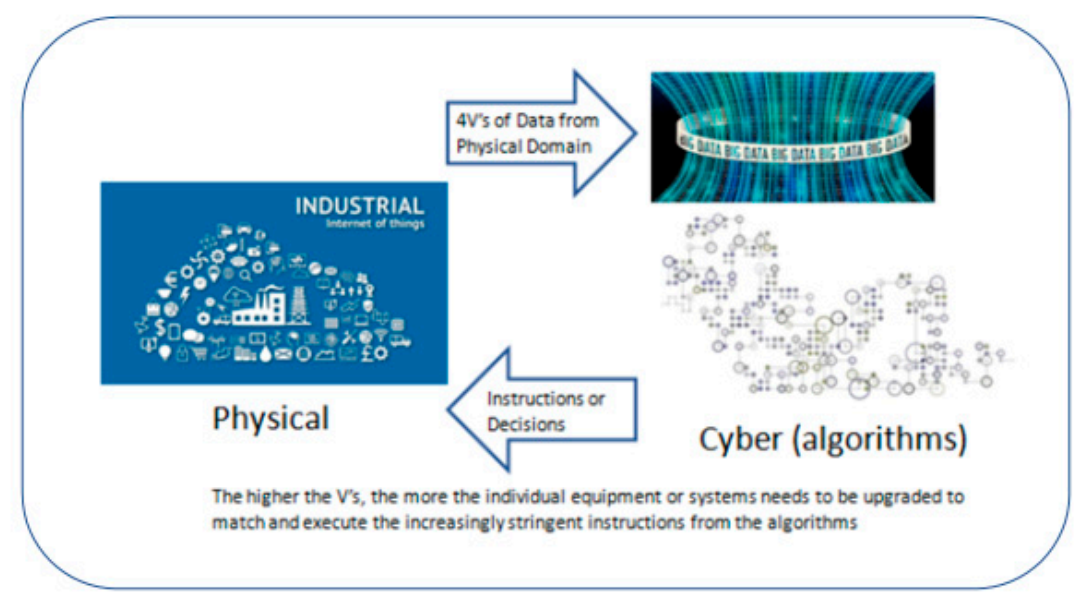

Figure 6. A rendition of the proposed interaction or feedback effects between the physical and cyber domains; higher V's of data would in turn demand higher processing capabilities in the physical system to execute instructions. This will trigger technology fusion in the individual product technology.

An instrumental technology which could facilitate the experimentation and understanding the effects of the co-evolution of both the cyber and physical sides, but which avoids incurring hardware costs is the notion of a "digital twins." A digital twin is a virtual model of a physical process, product, or service. The coupling of the virtual and physical worlds therefore now all take place on the digital domain and the experimentation on the variation of the physical side involves no building of a physical prototype which could be very prohibitive in costs. Many companies such as GE has adopted such technology e.g., a "digital windfarm" to simulate the joint effect or interaction of the variation of the design of the physical wind farm and its response to different control algorithms or analytics incorporating different ambient conditions. This will reveal new strategies or opportunities to reduce downtime, optimize yield, and to simply anticipate and address problems before they even occur.

\section{Ambidextrous Management Across Stages}

While the above motivates the managerial implication across the physical and cyber boundary [30], a more subtle theme of ambidextrous management is that of across the timeline [30]. As we have suggested in Section 5.3.2 (smart product as a service), product-centric firm will face an increasing diversity of devices and systems to be connected to their products, an increasing diversity of content, data to be generated, and an increasing diversity of developers and stakeholders to co-operate an increasing diversity of business models as industry make transition to Industry 4.0 era. There is a dynamic or evolutionary requirement that firms must anticipate such organizational challenges and complexities and choose a social technology which could manage both current and the future organizational challenges. The choice of social and coordination technology in the smart service era will enable or constrain a product-centric firm's capability to make transition to the Industry 4.0 era.

All in all, the managerial implications of industry's transitioning to 4.0 concern ambidextrous management across boundaries and time.

\section{Summary}

This paper could be summarized in terms of a simplified chronology of innovation (management) issues associated with a manufactured physical product (Figure 7) for a product-centric firm making the transition to the industry 4.0 era. 


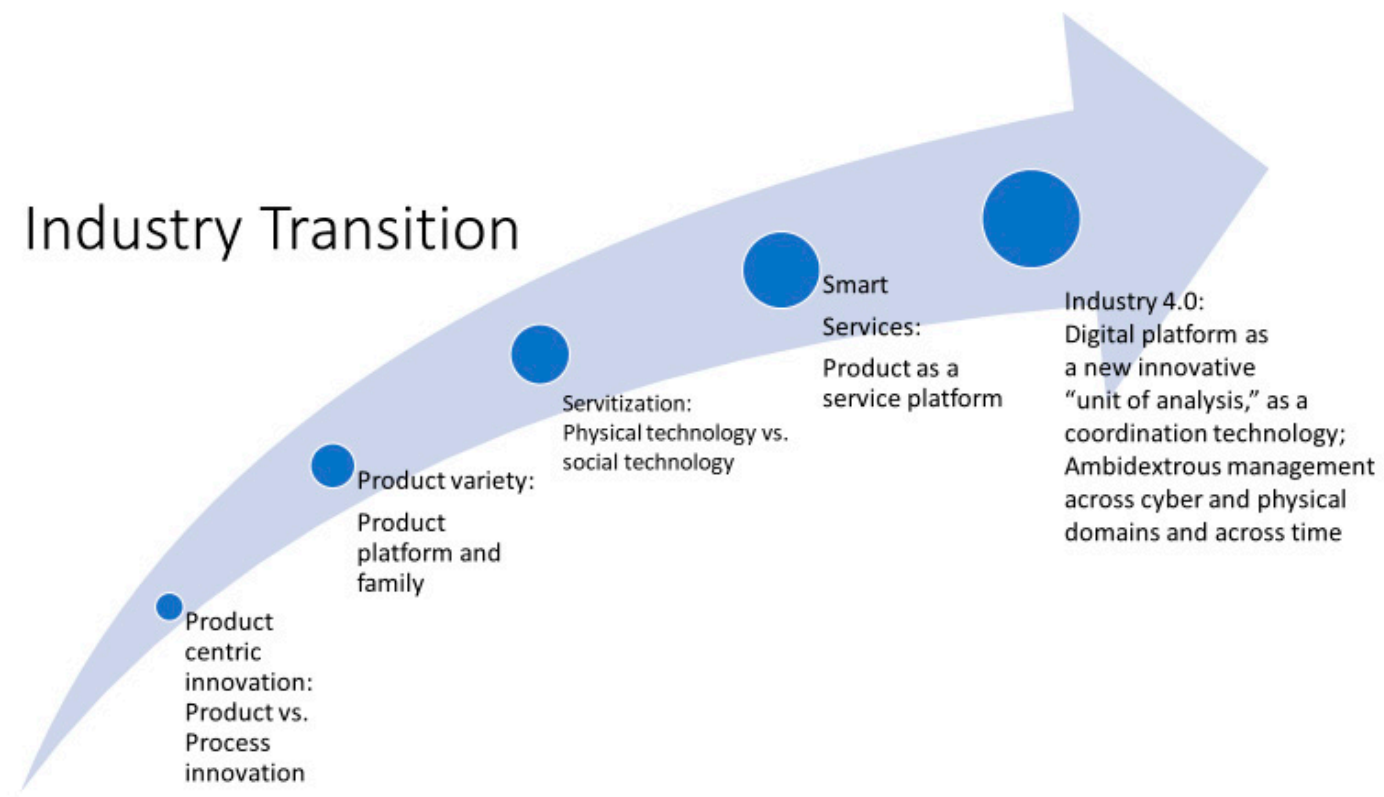

Figure 7. A proposed simplified chronology of the different stages of industry transition.

We start with the classical Abernathy Utterback product life cycle which postulated the division and direction of innovation efforts (product innovation vs. process innovation) before and after the emergence of a dominant standard (design) for the product. We also refine this closed and convergent classical model by suggesting that there is now a flurry of innovation activities beyond the production of a product artifact made possible due to sensors, connectivity, and intelligence technologies. The outlook is therefore an alternative product phase of open-endedness and divergence even after the product is made or produced and the new product life cycle never quite settles down to an equilibrium or steady state.

The next critical idea of innovation, once a product category is established, is the notion of competing by product variety or derivatives in order to capture the many finer micro-segments within a larger market. A key innovation challenge is how to be diverse and yet (cost) efficient because there is a fundamental trade-off between the two. Product platform leverages the static economy of scope among the production of the derivatives, due to sharing the same manufacturing and management infrastructure and investment. However, there is also a more important source of dynamic learning, namely cross learning, which involves knowledge transfer among production activities of different derivatives which helps to mitigate the variety-efficiency tradeoff. A change in product platform would usually involve a change in the architectural aspect which is more radical. Other innovation at the platform level would involve a company's opening up the (usually proprietary) product platform for external developers to customize upon the platform for local application objectives.

The next milestone is that of the emergence of services when product manufacturers increasingly move to downstream to capture revenues associated with servicing the products after they are purchased. The servitization of a product could be theorized or generalized as involving both new social technology (division of labor) and physical technology. With the retrofitting of many awareness and connectivity technologies to physical products, the physical products serve as (service) platforms so that many smart services could be developed or launched. Beyond smart services, which are about the operations and maintenance of products in the field, new and novel business models would also be developed which usually involve the re-positioning of the product itself. For those product firms which retain vertical integration to coordinate smart services and new business models development, they "fold in" all the development activities; for those product firms which involve external partners or stakeholders, they need to aggregate and build synergies with an appropriate coordination technology (and not by owning all these development). The smart service stage is an intermediate step to the 
next era of Industry 4.0. Firms' earlier organizational decisions or how they coordinate smart services activities could enable or constrain their future development opportunities in the Industry 4.0 era.

Currently, as we are entering into the new era of Industry 4.0, we see that massive number of devices and systems in production settings being connected and exchanging information among each other at different hierarchy levels. It is not only scaling up the coordination challenges in the smart service era, the processing of data of higher volume, velocity, veracity and variety is also posing unprecedented opportunities. Multi-sided digital platforms emerge as the quintessential coordination technology (social technology) in this epoch, orchestrating distributed third-party app developers to develop apps to be run on the networked systems in various Industry 4.0 scenarios. Product-centric manufacturing firms need to have the competencies to coordinate and tackle data complexities and exploit data opportunities in Industry 4.0 using open industry standards, APIs, or SDKs other than vertical integration because no one firm could be assumed to have all the capabilities to provide all the software development and data analytics capabilities: descriptive, diagnostic, predictive and prescriptive [1]. Due to the escalation of the $4 \mathrm{Vs}$ of data, physical product systems must concurrently be innovating via technology fusion or integration or open innovation to increase its product capabilities to respond to the more stringent instructions from powerful analytical algorithms developed in the cyber domain. The implicated product development capabilities of product-centric firms, along with the competencies to organize a digital platform to coordinate the development in the cyber or data domain, are the dual aspects of competition in the Industry 4.0 era.

Therefore, all point to the requirements of an ambidextrous strategy managing the co-evolution of (across) the cyber (digital) and physical channels and across time. For ambidextrous management across time, we fully subscribe to the concept and notion of innovator dilemma [32] and the importance for companies to adopt social and coordination technology, from a longitudinal perspective, to plan for and mitigate the coordination challenges as they make the transition to the industry 4.0 era. Companies which can manage both the product and cyber domains collectively and concurrently and their co-evolution and across timeline are more likely to harness the opportunities Industry 4.0 could offer with the least disruption.

Our biggest theoretical and conceptual contribution is that we have proposed the new conceptual construct [4] of digital platform as a new innovative "unit of analysis" during the industry 4.0 era for product centric firms. This "unit of analysis" is the holistic physical network of things and the apps developer community discovering values and patterns from the data generated from the industrial network of things. The product-centric (firm) needs to both differentiate and integrate these two sides in the digital platform and serve as an architect [4] to manage them ambidextrously across boundary and across time. Data from the digital platform will be an important competitive asset and to be reused by different apps developers. Digital platform owners also could provide many platform services to attract physical systems vendors to join in the physical side which will attract more developers to join the cyber side. The increasing return and virtuous cycle dynamic due to e.g. network externality, figures prominently in a digital platform. This is a marked departure from competition in the pre-digital manufacturing age when the innovative unit of analysis was primarily the product (platform) and the production process and the key economies are static economy of scale and production learning. Based upon this conceptual construct and inferred practical managerial implications, more specific company case studies in different verticals about why some firms could make this digital transition and why some firms apparently could not, will further substantiate theoretical and practice development.

\subsection{Future Research Directions}

\subsubsection{Competitive Research in the Industry 4.0 Era}

The digital platform with its associated APIs and SDK serves as a mechanism to economically coordinate follow-on development of apps to be run on the networked physical products. Shibata [33] suggested for the automotive industry that, as the industry is electrified and becomes standardized, i.e., 
the conventional manufacturing (process) advantages of specific manufacturers are eroding, increasing opportunities will emerge not from the manufacturing aspects of electric vehicles, but from the new apps to be developed and ported to the electric vehicles leading to the connected vehicle paradigm. The study of effects or leverages of a digital platform in the electro-mobility sector could follow the same logic discussed in this paper. However, more research could be advanced concerning how to substantiate the idea of the new "innovative unit of analysis" in the Industry 4.0 era at the firm or industry level, which comprises the smart and connected physical product (the automobile itself and its technologies) and the cyber domain, where the data from the connected automobile are processed. More integrative studies need to be performed beyond product development linkage aspects in order to understand the organizational field (shared assumptions and beliefs) [34] among stakeholders of the smart product industries and the managerial implications.

\subsubsection{Path Dependency and Transition to the Industry 4.0 Era}

While the following is about a specific company, it does possess general strategic implications. In the earlier days of FANUC, in the wake of the adoption of MPU and a modular architecture in system 6 series, it gradually opened up in both the hardware and software domains for a multi-vendor environment and for customers to participate in software development. Both of these factors allowed FANUC to learn the "culture" of openness and may pave the way to embrace the notion of an OPEN digital platform like FIELD, as described in this paper. This should inspire a new avenue for future empirical research concerning industry transition in terms of the continuity or path dependency effects of prior product architecture choice in the transition to the Industry 4.0 era.

Author Contributions: Conceptualization, K.S. and F.K.; validation, F.K.; formal analysis—K.S.; writing-original draft preparation, K.S.; writing-review and editing, K.S. and F.K. All authors have read and agreed to the published version of the manuscript.

Funding: This paper was presented as a keynote speech at SOItmC 2020, and the publishing fee was supported by SOItmC.

Conflicts of Interest: The authors declare no conflict of interest.

\section{References}

1. Porter, M.; Heppelmann, J. How Smart, Connected Products Are Transforming Companies. Available online: https://hbr.org/2015/10/how-smart-connected-products-are-transforming-companies (accessed on 31 August 2020).

2. Raff, S.; Wentzel, D.; Obwegeser, N. Obwegeser Smart products: Conceptual review, synthesis, and research directions. J. Prod. Innov. Manag. 2020, 1-26. [CrossRef]

3. Stankovic, J.A.; Sturges, J.W.; Eisenberg, J. A 21st Century Cyber-Physical Systems Education. Computer 2017, $50,82-85$.

4. Macinnis, D.J. A Framework for Conceptual Contributions in Marketing. J. Mark. 2011, 75, 136-154.

5. Abernathy, W.J. Utterback, J.M. Patterns of Industrial Innovation. Technol. Rev. 1978, 80, 40-47.

6. Abernathy, W.J. Productivity Dilemma: Roadblock to Innovation in the Automobile Industry; The Johns Hopkins University Press: Baltimore, MD, USA, 1978.

7. Kodama, F. Emerging Patterns of Innovation, Sources of Japan's Technological Edge; Harvard Business School Press: Brighton, MA, USA, 1995.

8. Chesbrough, H. Open Innovation-The New Imperative for Creating and Profiting from Technology; Harvard Business School Press: Brighton, MA, USA, 2003.

9. Shibata, T.; Yano, M. Dynamic Evolution of Product Architecture-Alternative View of Technical Progress of Numerical Controller, National Institute of Informatics. 2002. Available online: https://www.nii.ac.jp/ TechReports/public_html/02-002E.pdf (accessed on 20 November 2018).

10. Sanderson, S.; Uzumeri, M. Managing Product Families: The case of the Sony Walkman. Res. Policy 1995, 24, 761-782. 
11. Meyer, M.; Lehnerd, A. The Power of Product Platforms-Building Value and Cost Leadership; The Free Press: New York, NY, USA, 1997.

12. Smith, P.; Reinertsen, D. Developing Products in Half the Time-New Rules, New Tools, 2nd ed.; Wiley: Hoboken, NJ, USA, 1998.

13. Shum, K.L. Product Platform: Its Strategic Implications. In Proceedings of the MCPC Conference, Mass Customization and Personalization Conference Held at Technische Universitet Munchen, Munich, Germany, 6-8 October 2003.

14. Shum, K.L.; Watanabe, C. Towards a local learning (innovation) model of solar photovoltaic deployment. Energy Policy 2008, 36, 508-521.

15. Allmendinger, G.; Lombreglia, R. Four Strategies for the Age of Smart Services. Harv. Bus. Rev. 2005, 83, 131-134, 136, 138.

16. Shum, K.L. Rethinking Transition from Products to Services: A Physical Technology vs. Social Technology Approach; Intellectual Property Publishing House: Beijing, China, 2008; pp. 329-332.

17. Nelson, R. Physical and Social Technologies, and Their Evolution. 2003. Available online: https://pdfs. semanticscholar.org/9e4d/ba5631c30392413b2ddaff905622301929f5.pdf (accessed on 20 November 2018).

18. Tidd, J. Development of novel products through intraorganizational and interorganizational networks-the case of home automation. J. Prod. Innov. Manag. 1995, 12, 307-322.

19. Shum, K.L. Closed and Open PV (photo-voltaic) Deployment Models: Characteristics and Implications to the Transition to Smart PV-A Japan and US Comparison. Ph.D. Thesis, Department of Industrial Engineering and Management, Tokyo Institute of Technology, Tokyo, Japan, 2006.

20. Green, J.; Newman, P. Citizen utilities: The emerging power paradigm. Energy Policy 2017, 105, $283-293$.

21. Jacobson, D.; Brail, G.; Woods, D. APIs—A Strategy Guide; O’Reilly: Newton, MA, USA, 2012.

22. Kodama, F.; Shibata, T. Beyond Fusion Towards IOT by Way of Open Innovation; an investigation based on the Japanese machine tool industry 1975-2015. J. Open Innov. Technol. Mark. Complex. 2017, 3, 23.

23. Kodama, F. Learning Mode and Strategic Concept for the 4th Industrial Revolution. J. Open Innov. Technol. Mark. Complex. 2018, 4, 32.

24. Rosenberg, N. Perspectives on Technology; Cambridge University Press: Cambridge, UK, 1976; pp. 15-18.

25. Cusumano, M. The Business of Software; The Free Press: New York, NY, USA, 2004.

26. Paasivaara, M.; Lassenius, C. Communities of practice in a large distributed agile software development organization-Case Ericsson. Inf. Softw. Technol. 2014, 56, 1556-1577.

27. Coase, R. The Nature of the firm. Economica 1937, 4, 386-405.

28. Powell, W.M. Neither Market nor Hierarchy; Network Forms of Organization. In Research in Organizational Behavior; Staw, B.M., Cummings, L.L., Eds.; JAI Press: Greenwich, CT, USA, 1990; Volume 12, pp. $295-336$.

29. Arthur, B. Competing Technologies, Increasing Returns, and lock-in by historical event. Econ. J. 1989, 99, 116-131.

30. Tidd, J.; Bessant, J.R. Managing Innovation-Integrating Technological, Market and Organizational Change, 3rd ed.; Wiley: Hoboken, NJ, USA, 2005.

31. Shibata, T.; Baba, Y.; Kodama, M.; Suzuki, J. Managing ambidextrous organizations for corporate transformation: A case study of Fujifilm. RED Manag. 2019, 49, 455-469.

32. Christensen, C. The Innovator's Dilemma-When New Technologies Cause Great Firms to Fail; Harvard Business School Press: Brighton, MA, USA, 1997.

33. Shibata, T. Future of the Automotive Industry Strategies with a View to the Future of EVs and Beyond: Exploring the Applications of Technologies to Other Fields. 2018. Available online: https: //www.japanpolicyforum.jp/archives/economy/pt20180208120433.html (accessed on 20 November 2018).

34. Johnson, G.; Whittington, R.; Regnér, P.; Scholes, K.; Angwin, D. Exploring Strategy—Text and Cases, 11th ed.; Pearson: London, UK, 2017.

(C) 2020 by the authors. Licensee MDPI, Basel, Switzerland. This article is an open access article distributed under the terms and conditions of the Creative Commons Attribution (CC BY) license (http://creativecommons.org/licenses/by/4.0/). 